\title{
Assessment of Thermodilution Cardiac Output in Small Subjects
}

\author{
By Mark L. Callaghan, William H. Weintraub, and Arnold G. Coran
}

$\mathbf{S}$ EQUENTIAL DETERMINATIONS of cardiac output can provide useful information for the care of small infants and children. The commonly employed dye-dilution techniques are cumbersome and are limited in the frequency with which repeat studies can be performed. In contrast, thermodilution cardiac output determinations are easy to perform and can be repeated frequently; however, the practicality and accuracy of this technique have not been well established in small subjects. Specifically, the effects of different injectate sites and various injectate volumes and temperatures on the accuracy of the technique have not been evaluated. In addition, a comparison between thermodilution cardiac output and dye-dilution cardiac output, with these parameters varied, has not been investigated in small subjects during normovolemia and hypovolemia. Therefore the following study was undertaken.

\section{MATERIALS AND METHODS}

Twenty-one newly weaned puppies, ranging in weight from 1 to $4 \mathrm{~kg}$, were studied during normovolemic and hypovolemic states. Anesthesia was induced with intraperitoneal pentobarbital at $30 \mathrm{mg} / \mathrm{kg}$ and maintained with intermittent intravenous injections. Arterial and venous catheters were placed after bilateral femoral cutdowns. Vascular pressures were monitored with Statham P23Db transducers. Electrocardiographic and systemic arterial pressure tracings were monitored continuously. The puppies were heparinized at the start of each study.

A Waters* No. 5 French thermistor-tipped flow-directed catheter was positioned in the pulmonary artery using pressure tracings to identify the location of the catheter tip. The cather injection port was $15 \mathrm{~cm}$ proximal to the thermistor tip. Cardiac output was calculated via a specially designed Waters COR-100 analog computer using the following modification of the Stewart-Hamilton indicator-dilution formula:

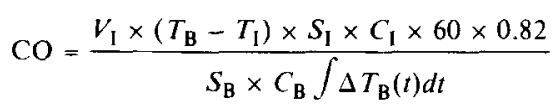

where $V_{\mathrm{I}}=$ volume of injectate $(\mathrm{ml}) ; T_{\mathrm{B}}, T_{\mathrm{I}}, S_{\mathrm{B}}, S_{\mathrm{I}}, C_{\mathrm{B}}$, and $C_{\mathrm{I}}=$ temperature, specific gravity, and specific heat of blood (B) and indicator (I); $0.82=$ empirical correction factor for indicator loss between injection site and delivery site. The computer analyzes the area under the dilution curve from its starting point to the downslope side at $75 \%$ of its peak. It then estimates the assumed exponential decay of the curve from this point.

Dye dilution was performed by injecting indocyanine green into the right atrium while an arterial dye curve was obtained using a femoral arteriovenous fistula and Holter pump as described by Arcilla and Rowe. ${ }^{1}$ Cardiac output was calculated by the same Waters COR-100 computer using the Stewart-Hamilton formula. After a $15-\mathrm{min}$ period of stabilization, normovolemic

\footnotetext{
*Waters Instruments, Rochester, Minn.

From the Section of Pediatric Surgery. Mott Children's Hospital and University of Michigan Medical School, Ann Arbor, Mich.

Presented before the 7th Annual Meeting of the American Pediatric Surgical Association, Boca Raton, Fla., April 29-May 1. 1976.

Address for reprint requests: Arnold G. Coran. M.D., Section of Pediatric Surgery, Room F7516. Mott Children's Hospital, Ann Arbor. Mich. 48109.

(c) 1976 by Grune \& Stratton, Inc.
} 
determinations were made. The puppies were then bled over $30 \mathrm{~min}$ to a mean arterial pressure of approximately $60 \mathrm{~mm} \mathrm{Hg}$. This was followed by a $\frac{1}{2}$-hr stabilization period. Further cardiac output measurements were then performed.

Paired determinations using cold saline $\left(2^{\circ} \mathrm{C}\right)$ and room-temperature saline $\left(23^{\circ} \mathrm{C}\right)$ versus dyedilution outputs were made. Paired determinations of different injectate volumes (between 1 and 5 $\mathrm{ml}$ ) were also performed. Inferior vena caval injection was compared with right atrial injection using an independently placed right atrial catheter, since the standard $15-\mathrm{cm}$ distance between injection port and thermistor tip routinely placed the delivery site slightly below the level of the diaphragm. The positions of all catheters were confirmed at autopsy. Statistical significance was determined with the paired $t$ test and correlation coefficients.

\section{RESULTS}

Sixty-two paired determinations of thermodilution cardiac output (C.O. Th) using cold saline $\left(2^{\circ} \mathrm{C}\right)$ and dye-dilution cardiac output (C.O. Dye) were performed (Fig. 1A). The outputs ranged from 0.17 to $1.46 \mathrm{liters} / \mathrm{min}$. There was no significant difference between the two techniques of cardiac output. The correlation coefficient $(r)$ was $0.92(p<0.001)$. In addition, the two mean values for cardiac output were not significantly different (C.O. Dye $=0.634$ liters/ $\min$, C.O. $\mathrm{Th}=0.638$ liters $/ \mathrm{min}$ ).

Sixty-four determinations of thermodilution cardiac output with roomtemperature saline $\left(23^{\circ} \mathrm{C}\right)$ were compared with dye-dilution outputs (Fig. 1B). These outputs also ranged from 0.17 to 1.46 liters $/ \mathrm{min}$. There was no significant difference between these two sets of numbers $(r=0.86, p<0.001)$. The mean values were 0.533 liters $/ \mathrm{min}$ and 0.620 liters $/ \mathrm{min}$ for thermodilution and dye-dilution cardiac outputs, respectively. The mean difference (C.O. Dye - C.O. Th) was 0.093 liters $/ \mathrm{min}$ or $15 \%$.

Forty-eight determinations of right atrial and inferior vena caval injection
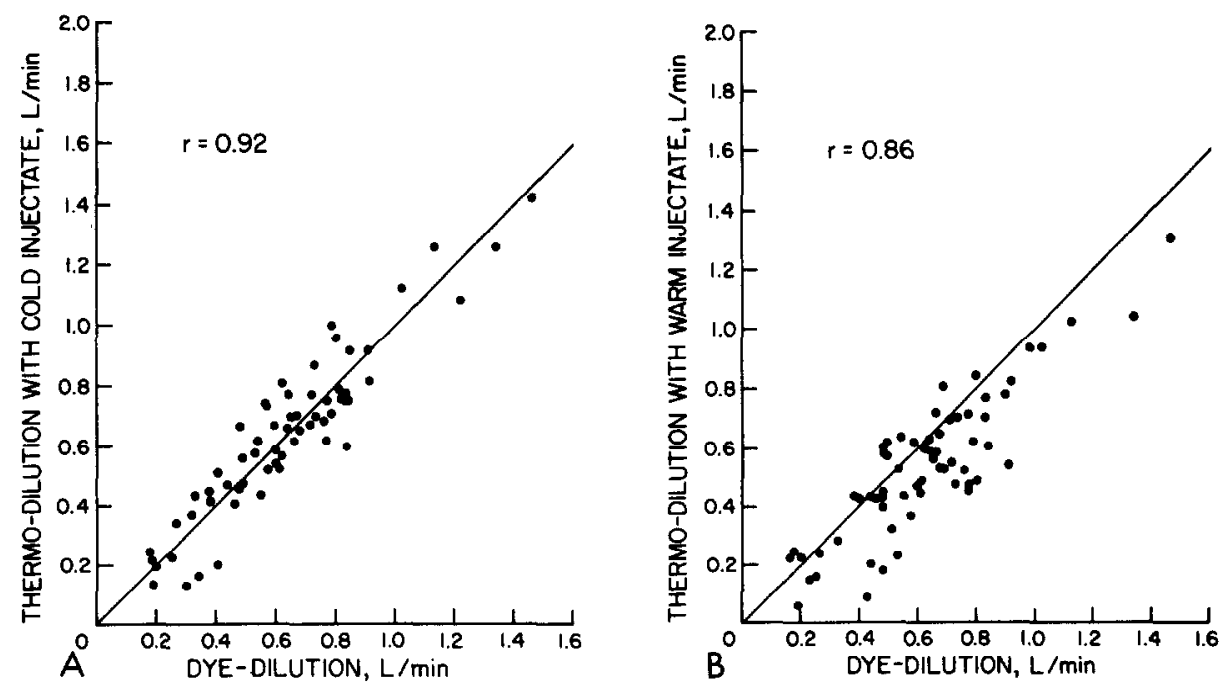

Fig. 1A. Comparison between dye-dilutin and thermodilution cardiac outputs using cold injectate.

Fig. 1B. Comparison between dye-dilutin and thermodilution cardiac outputs using warm injectate. 


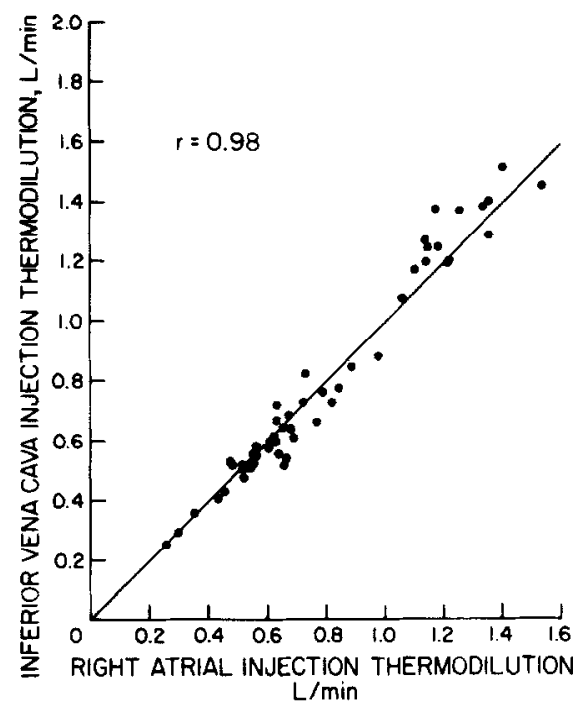

Fig. 2. The effect of injection site on thermodilution cardiac output.

were also compared (Fig. 2). Once again, there was no statistical difference in output using these two delivery ports $(r=0.98, p<0.001)$.

The effect of injectate volume on thermodilution cardiac output was investigated in 38 grouped measurements (Fig. 3). Cardiac output was determined by injecting 1 or $2 \mathrm{ml}$ of warm or cold saline and was then remeasured with sequential increases in volume. With both warm and cold saline, the difference between the initial and final measurement was not statistically significant (0.0028 liters $/ \mathrm{min}$ for warm saline and zero for cold saline).

Forty percent of all C.O. measurements were made during hypovolemia (mean blood pressure less than $60 \mathrm{~mm} \mathrm{Hg}$ ). In this subgroup, the correlation coefficient between dye-dilution and thcrmodilution (warm or cold saline)
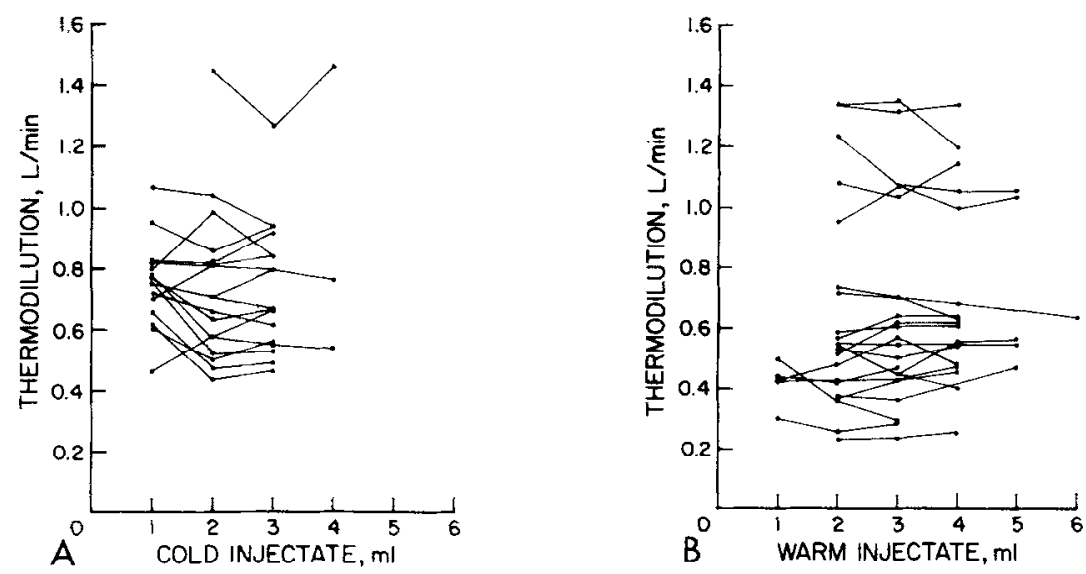

Fig. 3A. Effect of cold injectate volume on thermodilution-cardiac output.

Fig. 3B. Effect of warm injectate volume on thermodilution-cardiac output. 
cardiac output readings was $0.90(p<0.001)$, i.c., there was no significant difference between these two techniques.

\section{DISCUSSION}

Cardiac output determinations provide direct information about cardiac performance that can be useful in early recognition of the hemodynamic changes associated with shock, sepsis, and injury. Serial determinations can be especially helpful in monitoring the clinical course and in determining the therapy of such conditions. With the advent of simple analog computers, cardiac output can now be performed at the bedside with almost instantaneous results. The dye-dilution technique, using indocyanine green, has become the clinical standard of cardiac output measurement. However, this technique is poorly suited to the small patient because both central venous and arterial catheters are required and significant amounts of blood for calibration and output determination must be withdrawn. The thermodilution method eliminates the need for blood withdrawal and arterial catheterization. It also offers the theoretical and practical advantages of minimum recirculation, ease of calibration, and capability of frequent determinations.

Several reports have demonstrated good correlation between dye-dilution and thermodilution methods. ${ }^{2-5}$ However, these studies were carried out in adult subjects under normovolemic conditions. We found that paired thermodilution and dye-dilution estimates correlated well in both normovolemic and hypovolemic states, including hemorrhagic shock. While the accuracy of dye dilution at low-output states has been questioned, 6.7 the technique has been accepted as the reference standard, and its usefulness over a wide range of clinical situations has been well demonstrated.

While the apparent advantages and accuracy of the thermodilution method would support its use in small subjects, the volume and temperature of the injectate needed to provide accurate results must be determined to fully assess its practical usefulness in neonates and small children. Ganz et al. ${ }^{2}$ believe cold saline $\left(0-5^{\circ} \mathrm{C}\right)$ is the indicator of choice for thermodilution cardiac output because of a greater signal-to-noise ratio. Noise in this instance refers to the baseline temperature fluctuations with respiration in the pulmonary artery. Ganz et al. suggest that if room-temperature saline is used, a greater quantity of injectate would be required. In our studies, cold saline correlated slightly better with dye dilution than did room-temperature saline, but the difference was not statistically significant ( $r=0.92$ versus 0.86 ). In addition, the volume of the injectate did not appear to affect the output value significantly in the range lested. From a practical point of view, our injectate of choice is $2 \mathrm{ml}$ of cold saline.

Since only small volumes of saline are required to provide acclirate results, frequent determinations, even in the neonate, can be performed. Because of the neonate's well-known intolerance to hypothermia, room-temperature saline might be preferred to cold saline; however, no adverse effects such as arrythmias or systemic hypothermia from the repeated injections of cold saline were noted.

Injection time is also a factor in determining the accuracy of thermodilution cardiac output. This fact limits the volume of injectate that can be expected to give reliable results. Injection time is assumed to be instantaneous, even though an injection lasting $1 \mathrm{sec}$ is common. ${ }^{8}$ While an injection lasting a few seconds 
has been shown to give satisfactory results, ${ }^{9}$ Enghof ${ }^{8}$ found that $1-$ sec injections correlated better with Fick cardiac outputs than did those lasting 4 to $8 \mathrm{sec}$. In our small subjects, the use of the small No. 5 French catheters resulted in prolongation of the injection time and distortion of the dilution curves when more than $5 \mathrm{ml}$ were injected.

Two requirements of any dilution technique are that adequate mixing of the indicator take place and that none of the indicator be lost before sampling. Injection into the right atrium has been shown to provide adequate mixing when sampling is done from the pulmonary artery. ${ }^{10}$ However, when using catheters with a fixed distance between injection port and thermistor tip in pediatric patients of constantly changing sizes, nonatrial injection is inevitable. We found that significant caval displacement of between 5 and $7 \mathrm{~cm}$ does not affect the accuracy of the technique. This finding agrees with that of Hosie," who found that important heat loss does not take place in the walls of large vessels. Since caval displacement does not adversely affect output values, a single fixeddistance catheter can be used to perform thermodilution cardiac output in a wide range of pediatric patients. It appears that a $10-\mathrm{cm}$ distance would be more appropriate in the pediatric age group; we are currently assessing catheters with these dimensions.

\section{SUMMARY}

Thermodilution cardiac output determinations were compared with dyedilution measurements in normovolemic and hypovolemic puppies. Good correlation was achieved with small volumes of cold and warm saline. Injectate volumes and significant caval displacement of the injectate port did not significantly affect thermodilution output measurements. This study demonstrates that thermodilution is a reliable and practical method of cardiac output determination in small subjects and suggests that this technique may be useful in the clinical mangement of neonates and small infants.

\section{REFERENCES}

1. Arcilla RA, Rowe MI: Modified dye dilution technique for cardiac output studies in tiny subjects. Am Heart J 77:798, 1969

2. Ganz W. Donoso R, Marcus HS, et al: A new technique for measurement of cardiac output by thermodilution in man. Am $\mathbf{J}$ Cardiol 27:392, 1971

3. Solomon HA, San Marco MA, Ellis RT, et al: Cardiac output determination: Superiority of thermal dilution. Surg Forum 20:28, 1969.

4. Merjavy JP, Hahn J, Barner HB: Comparison of thermodilution cardiac output and electromagnetic flow meter. Surg Forum 25:145. 1974

5. Olsson B, Pool J, Vandermoten E, et al: Validity and reproducibility of determination of cardiac output by thermodilution in man. Cardiology 55:136, 1970

6. Blackburn JP, Leigh JM: Effect of infection and sampling site on dye dilution curves during hypotension. Cardiovasc Res 6:741, 1972

7. Wiberg-Jirgensen F, Engell HC, Rygg IH: Reproducibility of cardiac output determination by dye dilution technique in patients with valvular disease. Dan Med Bull 22:1, 1975

8. Enghoff E, Sjögren S: Thermic dilution for measurement of cardiac output in the pulmonary artery in man in relation to choice of indicator volume and injection time. Ups $J$ Med Sci $78: 33,1973$

9. Pavek K, Karoviv K: Rapid estimation of areas under thermodilution curves. $Z$ Kreislaufforschung 58:1109, 1969

10. Branthwaite MA, Bradley RD: Measurement of cardiac output by thermodilution in man. J Appl Physiol 24:434, 1968

11. Hosie KF: Thermal dilution techniques. Circ Res 10:491, 1962 


\section{Discussion}

M. Rowe (Miami): There are significant right-to-left shunts in many of the patients in whom we wish to measure cardiac output. Included are patients who have diaphragmatic hernia, respiratory distress syndrome, and necrotizing enterocolitis. What we are interested in about these patients is systemic blood flow. Utilizing the thermal dilution technique with the catheter on the right side of the heart, it is difficult to interpret what the effect of right-to-left shunts would be. In the experimental animals chosen, puppies over 2 wk of age, there were no right-to-left shunts. This paper clearly demonstrates that in patients without right-to-left shunts, very accurate cardiac outputs may be determined by using the thermodilution probe on the venous side of the circulation. It would be challenging to see if a technique could be developed to measure output on the left side of the heart using thermodilution.

F. Ehrlich (Richmond): We have had some difficulty in passing the standard No. 5 catheter from above. We recently obtained a No. 3 catheter with all of the same capabilities as the No. 5 . We then encountered a very unusual problem. We passed the No. 3 catheter from above through the internal jugular, and it floated very nicely into the pulmonary artery. After a short period of time our pressure tracing disappeared. We thought that the port had been clotted over, and we irrigated it. When we still didn't get a pressure recording we looked at the cardiac tracing and realized the dog was in acute right ventricular failure. This was a $1-1 \frac{1}{2}-\mathrm{kg}$ puppy who promptly expired. We autopsied the animal, and what had happened was that in floating the catheter out, the balloon had totally occluded his main pulmonary artery. We subsequently reproduced this unfortunate circumstance in another puppy. The catheter wedged in these small animals, just as I' $m$ sure it could in a neonate, in a place much too proximal.

$M$. Callaghan (closing): We have had some clinical experience in cardiac patients in whom we have put the catheters through the internal jugular, using the Seldinger technique, prior to surgery. The smallest child was age $5 \mathrm{yr}$. This has gone well, but we haven't tried it on younger patients.

In response to Dr. Rowe's question, I believe that intracardiac shunts would not lend themselves well to thermodilution output techniques. We don't have any good information about peripheral shunts.

We've had a similar experience when we didn't get any pressure tracings, but in this instance, the broken balloon had occluded the lumen of the catheter. It should be mentioned that the balloon, once properly positioned, should only be inflated for brief periods, when pulmonary wedge pressures are desired. This technique is being used more and more frequently in adults, and over the next few years we believe it will be more commonly used in the critically ill younger child. 